\title{
Determinants of Health Expenditures: Stylized Facts and a New Signal
}

\author{
Kei Hosoya \\ Faculty of Economics, Tohoku Gakuin University, Sendai, Japan \\ Email: khosoya@mail.tohoku-gakuin.ac.jp
}

Received 13 October 2014; revised 17 November 2014; accepted 28 November 2014

Copyright (C) 2014 by author and Scientific Research Publishing Inc.

This work is licensed under the Creative Commons Attribution International License (CC BY). http://creativecommons.org/licenses/by/4.0/

c) (i) Open Access

\section{Abstract}

This article further investigates the determinants of health expenditures by using aggregate data. Specifically, a panel data analysis of 25 OECD countries reveals that under several model specifications, the proxy for population ageing has no effect on health costs in accordance with recent findings. In contrast to this well-known result, an additional estimation conducted to check robustness revealed that the ageing variable becomes positive and significant. The significant effect may provide a new signal for a determinant of health expenditures. This result suggests that ageing is an important factor that cannot be ignored when considering variations in health expenditures.

\section{Keywords}

Ageing, Health Expenditures, OECD, Panel Data

\section{Introduction}

This article further investigates the determinants of health expenditures, which have been widely examined in econometric analyses of health care services. For this empirical study, OECD Health Data are used to construct a cross-country panel dataset and examined several issues by standard analytical methods. ${ }^{1}$

In previous studies on the determinants of per capita health expenditures, the age structure of a country's population (i.e., ageing of the population) has been considered an influential factor in increased expenditures in the health care sector, along with other important factors such as income and technological progress (Getzen, [1]; Norton, [2]; OECD, [3]). ${ }^{2}$ Numerous studies, including Hitiris and Posnett [4], have used ageing as a factor

\footnotetext{
The dataset is available from the author upon request.

${ }^{2}$ The ratio of older people (i.e., persons over the ages of $65,70,75,80$, etc.) to the entire population is often used as an index of population ageing in empirical studies.
} 
when examining health care expenditures. However, some relatively recent analyses using aggregate (macro) data, including Barros [5], Gerdtham et al. [6], and Herwartz and Theilen [7], have found negative or insignificant estimates for ageing variables, contrary to general predictions. These recent findings suggest that population ageing has no significant effect on variations in aggregate health expenditures. ${ }^{3}$ Similar findings are also obtained in microeconometric studies, including Felder et al. [11], Werblow et al. [12], and Zweifel et al. [13]. In these studies, the effects of ageing on health expenditures have been referred to as a "red herring hypothesis". ${ }^{4}$

Although much of the empirical evidence shown in macro and micro analyses depends on the weak explanatory power of an ageing variable, we reexamine this point based on the importance placed on the findings of Cutler [18]. Cutler commented, in regard to some studies calling the effects of population ageing on health expenditures a red herring, that the relevancy of ageing factors possibly varies in response to changes in the future health environment. Moreover, the rapid evolution of ageing societies in developed countries such as Japan is without precedent, and it would be quite natural for a change in the existing relationship between ageing and health expenditures to occur in such countries. If changes are observed, then special attention should be given to health care policy in these countries. Recently, in addition to the importance of the proximity of death for health cost determinants, as highlighted by Zweifel et al. [13], Dormont et al. [19] reevaluate the importance of the ageing factor according to the graphical analysis by Yang et al. [20]. Against this background, a reexamination of this issue is now useful.

To reexamine the impacts of population ageing given our analytical aim described above, we employ samples targeting periods of time in which societal ageing progressed rapidly. Although our primary goal is to examine the relationship between ageing and health costs, we also investigate the effects of other important variables including income level and proxies for the system of medical service. This approach is the notable feature of the present study compared with the literature, where focus is placed upon long-run economic relationships among some major variables. Baltagi and Moscone [21] provide one such example: they examine the non-stationarity and cointegration properties between per capita health care expenditure and per capita GDP. Furthermore, it is interesting to examine whether differences in estimation methods and the selection of explanatory variables affect the impact of population ageing on health expenditures. As shown in Baltagi and Moscone [21], estimates for ageing variables are sensitive to estimation methods. Therefore, we address such problems by using standard panel data analysis with a unified test procedure.

The rest of the article is organized as follows. Section 2 explains the econometric model and data employed in this study. Section 3 presents the estimation results. Lastly, Section 4 presents the study's conclusions.

\section{Model Specification and Data}

We developed a standard panel regression approach, which is a familiar one in the study of the determinants of health care expenditures. As the benchmark panel regression model, the individual-specific effects model (the fixed effects (FE) or random effects (RE) model) is specified as follows:

$$
\mathrm{HE}_{i t}=a_{i}+\alpha \mathrm{GDP}_{i t}+\beta \mathrm{POP}_{i t}+\mathbf{x}_{i t}^{\prime} \gamma+\varepsilon_{i t}
$$

where $i=1, \cdots, N$ denotes a cross-section index of countries, and $t=1, \cdots, T$ denotes the time-series index. ${ }^{5}$ The dependent variable in Equation (1) is the logarithm of real per capita health expenditures (HE). Real GDP per capita (GDP) and the ratio of the population aged 65 and over to the total population (POP65) are two fundamental variables in our regression analysis. The vector $\mathbf{x}$ corresponds to a set of explanatory (control) variables explained below. $\varepsilon$ is the error term. Note that all variables in Equation (1), including the variable on the left hand side but not the dummy variable, are expressed as natural logarithms. This implies that the functional form be a log-log specification, and thus we can interpret the estimated coefficients $\alpha, \beta$, and $\gamma$ as standard elasticities.

\footnotetext{
${ }^{3}$ A survey article by Gerdtham and Jönsson [8] remarked that, on the whole, there is little evidence to support the explanatory power of an ageing variable. On the other hand, a significant relationship is frequently found when one employs data at the provincial or state level, rather than at the country level (Di Matteo and Di Matteo, [9]; Wang, [10]).

${ }^{4}$ On the other hand, some studies have argued against this view (Dow and Norton, [14]; Getzen, [15]; Salas and Raftery, [16]; Seshamani and Gray, [17]).

${ }^{5}$ If an unobserved random variable $a_{i}$ is correlated (uncorrelated) with explanatory variables, Equation (1) corresponds to the FE (RE) model.

${ }^{6}$ Most variables were extracted from OECD Health Data 2008. World Development Indicators 2007 are used for FLABOUR and POPD.
} 
Here the unbalanced panel dataset includes 11 variables for 25 OECD countries over the period 1985-2006. ${ }^{6}$ The variables are listed in Table 1. In the literature, the fundamental variable GDP is widely used for studying health expenditure determinants (Gerdtham and Jönsson, [8]). The highlight of the present analysis is the behaviour of the sign and the significance of the estimated coefficient for POP65. Namely, when POP65 has a positive value, population ageing is a potential source of rising health costs. We also consider POP14, the ratio of the population aged 0 - 14 to the total population, as the variable for the population age structure. An increase in the share of young people within the population appears to reduce health costs (Mosca, [22]).

As other control variables, the following three variables reflecting the supply side and institutional characteristics of health care are examined: ABED, PUBE, and DCOVER. ABED is acute-care bed density, an increase in which is associated with higher health expenditures. Following Baltagi and Moscone [21], we also consider the intensity of public engagement in overall health expenditures. This is captured by the variable PUBE, corresponding to the share of public health expenditures out of total health expenditures. We assume that a higher share will increase health costs. In association with PUBE, an institutional dummy variable DCOVER is included in the regression equation, and takes the value 1 if the relevant country has an above average value for health care coverage (\% of total population) each year, or 0 otherwise. ${ }^{7}$ This variable accounts for the level of improvement in publicly provided health care systems.

In addition to the abovementioned variables directly related to health, the following socioeconomic variables are also included in the regression analysis: FLABOUR, POPD, and UNEMPLOY. FLABOUR denotes the percentage of female labour in the productive female population (age 15 - 64). This is one measure of the labour force participation rate of women, and we expect that a rise in this measure stimulates health expenditures due to increased household income. Following Crivelli et al. [23], we consider population density (POPD) as a proxy for the advancement of urbanization. A high population density is hazardous to human health, and it seems probable that rising health costs would follow. However, urbanization undoubtedly also leads to improvements in public health, which may decrease health expenditures. Accordingly, the influence of urbanization measured by population density should be judged in light of the empirical results presented below. Unemployment rate (UNEMPLOY) is a variable that reflects the macroeconomic environment. As Mosca [22] pointed out, a rise in this rate has a strong impact on human health and thus increases health costs.

When studying health expenditure determinants, it is important to include factors related to medical care technology into the regression equation. As Newhouse [24] noted, technological change in the health care sector conceivably has a significant impact on health costs because of its cost-increasing nature. Unless taking on a residual approach to technological change, however, assessing the impact of medical care technologies is difficult. If we tentatively restrict technological factors to medical equipment, we fail to extract sufficient samples for

Table 1. List of variables.

\begin{tabular}{cc}
\hline Symbol & Description of the variable \\
HE & Per capita real health expenditure (US \$, PPP) \\
GDP & Per capita real GDP (US \$, PPP) \\
POP65 & \% population aged 65 and over \\
POP14 & \% population aged 0 - 14 \\
ABED & Number of acute-care beds per 1000 population \\
FLABOUR & \% female labour from female population aged 15 - 64 \\
POPD & Number of people per sq. km \\
PUBE & Public health expenditure as \% of total health expenditure \\
UNEMPLOY & \% unemployment in labour force \\
DCOVER & Dummy variable for health coverage \\
TIME & Time variable \\
\hline
\end{tabular}

\footnotetext{
${ }^{7}$ We calculate the average value using the original OECD Health Data 2008 database. For all 30 countries over the period 1970-2006, the
} calculated average value for coverage (COVER) is about $93.42 \%$. Consequently, DCOVER $=1$ if COVER $\geq 93.42,0$ otherwise. 
computed tomography (CT) scanners and magnetic resonance imageing (MRI) in the current OECD Health Data. Thus, we employ an indirect and simple approach that evaluates the effects of medical care technologies. Following Crivelli et al. [23], Mosca [22], and others, we include a time variable (TIME) in the regression equation. This variable is specified as a linear trend over time. We can interpret a positive coefficient for TIME to be an indication that technological change leads to an increase in health costs.

The above are all of the variables used in this study. Summary statistics for 25 countries over the period 19852006 are reported in Table 2. Note that, in the FE model, the status of coverage may be eliminated as a fixed effect. Accordingly, we estimate the FE model without DCOVER.

\section{Estimation Results}

\subsection{Benchmark Estimations}

Table 3 shows benchmark estimation results from variations of Equation (1). Columns (1a)-(1c) show a set of standard panel estimations: pooled, FE, and RE. As is well known, by practicing a series of unified tests we can select a suitable model. The choice between the pooled and FE models is examined by an $F$ test. Along this line, the choice between the pooled and RE models is examined by the Breusch and Pagan (B-P) test, based on the Lagrange multiplier (LM) statistic. ${ }^{8}$ Finally, a comparison between the FE and RE models is conducted by using the Hausman test. ${ }^{9}$ According to the test results shown at the bottom of Table 3 (we report the $p$-value corresponding to each test), the FE model is the preferred specification, so we start with a detailed exploration of the results in Column (1b). ${ }^{10}$

Income elasticity corresponding to the estimated coefficient of GDP is smaller than unity, suggesting that health care service is a necessary good. More concretely, a 1\% point increase in GDP leads to health expenditures increasing by $0.95 \%$ points, and the coefficient is statistically significant at the $1 \%$ level. Some early studies at macro or national levels have claimed that income elasticity is greater than unity (i.e., a luxury good), but characteristics of a non-luxury good for health care have been proposed in the literature, including the relatively recent contributions of Gerdtham et al. [6], Mosca [22], and others.

As noted before, in this article, the effects of a country's age structure will be a central issue. The rate of population ageing POP65 is not significant, which agrees with recent findings including those from microeconometric studies. Incidentally, if POP65 rises by $1 \%$, total health costs increase by $0.05 \%$. Also, the ratio of younger people to the total population (POP14), gives an insignificant estimate.

Next we examine estimates for the supply side and institutional variables. The coefficient for ABED shows the expected sign but is insignificant; thus, bed density has no impact on health costs within the limits of this estimation. The estimate for public health expenditures (PUBE), has a positive sign and is statistically significant

Table 2. Summary statistics 1985-2006.

\begin{tabular}{ccccc}
\hline Variable & Mean & SD & Min & Max \\
\hline POP65 & 13.32 & 3.61 & 4.10 & 20.80 \\
POP14 & 20.08 & 5.16 & 13.60 & 42.00 \\
ABED & 4.39 & 1.92 & 1.00 & 12.30 \\
FLABOUR & 59.18 & 11.91 & 27.20 & 81.90 \\
POPD & 133.30 & 124.91 & 2.05 & 989.15 \\
PUBE & 70.66 & 13.87 & 30.90 & 97.40 \\
UNEMPLOY & 7.45 & 4.09 & 0.50 & 23.90 \\
\hline
\end{tabular}

Note: All variables are shown except for HE, GDP, DCOVER, and TIME.

\footnotetext{
${ }^{8}$ In both of these tests the model corresponding to the null hypothesis is the pooled model.

${ }^{9}$ The model corresponding to the null hypothesis is the RE model.

${ }^{10}$ The FE estimation can remove the problem of arbitrary correlation between the error terms caused by the unobserved explanatory variables and the observed explanatory variables in the model (see, for example, Wooldridge, [25]).
} 
Table 3. Estimation results (1).

\begin{tabular}{|c|c|c|c|}
\hline & (1a) & (1b) & (1c) \\
\hline \multirow[t]{2}{*}{ GDP } & $0.942^{* * *}$ & $0.949^{* * *}$ & $0.934^{* * *}$ \\
\hline & $(0.009)$ & $(0.010)$ & $(0.008)$ \\
\hline \multirow[t]{2}{*}{ POP65 } & $0.868^{* * *}$ & 0.047 & $0.233^{* * *}$ \\
\hline & $(0.050)$ & $(0.084)$ & $(0.072)$ \\
\hline \multirow[t]{2}{*}{ POP14 } & $0.384^{* * *}$ & -0.053 & 0.063 \\
\hline & $(0.085)$ & $(0.088)$ & $(0.082)$ \\
\hline \multirow[t]{2}{*}{ ABED } & $0.061^{* * *}$ & 0.045 & 0.052 \\
\hline & $(0.021)$ & $(0.038)$ & $(0.035)$ \\
\hline \multirow[t]{2}{*}{ FLABOUR } & $0.179^{* * *}$ & $0.204^{* *}$ & $0.326^{* * *}$ \\
\hline & $(0.044)$ & $(0.084)$ & $(0.074)$ \\
\hline \multirow[t]{2}{*}{ POPD } & $-0.050^{* * *}$ & 0.207 & $-0.036^{*}$ \\
\hline & $(0.006)$ & $(0.175)$ & $(0.019)$ \\
\hline \multirow[t]{2}{*}{ PUBE } & $-0.385^{* * *}$ & $0.246^{* * *}$ & $0.141^{* *}$ \\
\hline & $(0.036)$ & $(0.062)$ & $(0.058)$ \\
\hline \multirow[t]{2}{*}{ UNEMPLOY } & -0.017 & $0.046^{* * *}$ & $0.041^{* *+}$ \\
\hline & $(0.012)$ & $(0.010)$ & $(0.011)$ \\
\hline \multirow[t]{2}{*}{ DCOVER } & $-0.263^{* * *}$ & & $-0.072^{*}$ \\
\hline & $(0.019)$ & & $(0.043)$ \\
\hline \multirow[t]{2}{*}{ TIME } & $0.262^{* * *}$ & $0.280^{* * *}$ & $0.290^{* *+*}$ \\
\hline & $(0.034)$ & $(0.047)$ & $(0.033)$ \\
\hline$R^{2}$ & 0.968 & 0.688 & 0.927 \\
\hline Observations & 443 & 443 & 443 \\
\hline \multicolumn{4}{|c|}{ Specification tests ( $p$-value): } \\
\hline$F$ test & & .000 & \\
\hline B-P test & & .000 & \\
\hline Hausman test & & .000 & \\
\hline
\end{tabular}

Note: Constant term is included in each regression. Sample size is 25. Standard errors are shown in parentheses. ${ }^{* * *},{ }^{* *},{ }^{*}$ denote significance at 1,5 , and $10 \%$ levels, respectively.

at the $1 \%$ level, as in Baltagi and Moscone [21].

The three explanatory variables describing socioeconomic and macroeconomic conditions are interesting. The elasticity of FLABOUR is positive and significant at the $5 \%$ level, indicating that total health expenditures rise together with the rate of female labour force participation. This effect is generally ascribed to the social advancement of women, which enhances household income levels. As noted before, the advancement of urbanization (captured by POPD in this study) has a complex impact on health expenditures. Because the coefficient for POPD is positive but insignificant, this result tells us that urbanization has no relevance to national health expenditures. ${ }^{11}$ As expected, the rate of unemployment (UNEMPLOY) has a significant influence on health ex-

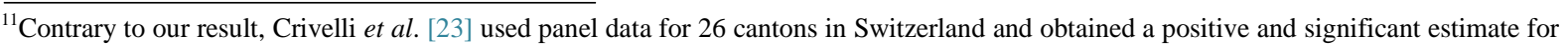
population density. 
penditures. The estimated coefficient is positive-a $1 \%$ increase in the unemployment rate leads to health costs rising by about $0.05 \%$ points - showing that addressing employment issues in the macroeconomy is related to health care issues, and thus raises some important implications.

Finally, we find that the time variable TIME is positive and significant at the $1 \%$ level. This implies that the sample countries transform gradually into a high-cost structure, probably due to technological change in the medical care and pharmaceutical sectors.

\subsection{Robustness of the Benchmark Results}

In this subsection, we examine the robustness of the benchmark estimations. Comparing the correlation coefficients among the explanatory variables, we find that our essential variable POP65 is highly correlated with POP $14 .{ }^{12}$ As is well known, high correlation among the regressors may produce a multicollinearity problem. In light of this, reestimating (1b) and (1c) without POP14 yields the results of columns (2a) and (2b) in Table $4 .^{13}$

Table 4. Estimation results (2).

\begin{tabular}{|c|c|c|c|c|}
\hline & (2a) & (2b) & (3a) & (3b) \\
\hline \multirow[t]{2}{*}{ GDP } & $0.946^{* * *}$ & $0.936^{* * *}$ & $0.943^{* * *}$ & $0.935^{* * *}$ \\
\hline & $(0.009)$ & $(0.008)$ & $(0.008)$ & $(0.007)$ \\
\hline \multirow[t]{2}{*}{ POP65 } & 0.077 & $0.192^{* * *}$ & 0.056 & $0.121^{* *}$ \\
\hline & $(0.069)$ & $(0.057)$ & $(0.053)$ & $(0.048)$ \\
\hline \multirow[t]{2}{*}{ ABED } & 0.046 & 0.050 & & \\
\hline & $(0.038)$ & $(0.035)$ & & \\
\hline \multirow[t]{2}{*}{ FLABOUR } & $0.224^{* * *}$ & $0.311^{* * *}$ & $0.209^{* * *}$ & $0.261^{* * *}$ \\
\hline & $(0.077)$ & $(0.073)$ & $(0.068)$ & $(0.064)$ \\
\hline \multirow[t]{2}{*}{ POPD } & 0.169 & $-0.037^{* *}$ & 0.177 & -0.027 \\
\hline & $(0.164)$ & $(0.019)$ & $(0.149)$ & $(0.023)$ \\
\hline \multirow[t]{2}{*}{ PUBE } & $0.244^{* * *}$ & $0.154^{* * * *}$ & $0.286^{* * *}$ & $0.249^{* * *}$ \\
\hline & $(0.061)$ & $(0.057)$ & $(0.052)$ & $(0.049)$ \\
\hline \multirow[t]{2}{*}{ UNEMPLOY } & $0.045^{* * *}$ & $0.042^{* * * *}$ & $0.043^{* * *}$ & $0.040^{* * *}$ \\
\hline & $(0.010)$ & $(0.011)$ & $(0.009)$ & $(0.009)$ \\
\hline \multirow[t]{2}{*}{ DCOVER } & & -0.068 & & \\
\hline & & $(0.044)$ & & \\
\hline \multirow[t]{2}{*}{ TIME } & $0.289^{* * *}$ & $0.285^{* * *}$ & $0.271^{* * *}$ & $0.276^{* * *}$ \\
\hline & $(0.044)$ & $(0.032)$ & $(0.030)$ & $(0.021)$ \\
\hline$R^{2}$ & 0.745 & 0.924 & 0.716 & 0.901 \\
\hline Observations & 443 & 443 & 489 & 489 \\
\hline \multicolumn{5}{|c|}{ Specification tests ( $p$-value): } \\
\hline$F$ test & .000 & & .000 & \\
\hline B-P test & .000 & & .000 & \\
\hline Hausman test & .000 & & .000 & \\
\hline
\end{tabular}

Note: See Table 3.

${ }^{12}$ The correlation coefficient in question is $r(\mathrm{POP} 65, \mathrm{POP} 14)=-0.91$.

${ }^{13}$ We report the results of the FE and RE estimations only. 
Since the three specification tests put forward the FE model, let us further consider the results for (2a). The estimated coefficients for fundamental variables GDP and POP65 remain much the same as before. We can therefore verify that population ageing barely affects health expenditures. Although the estimates of the other variables are similar to those of (1b), changes in the following three points should be noted. First, the significance level of the estimate for FLABOUR becomes higher; second, technological change in the health sector (captured by TIME) still has high explanatory power; and third, the goodness of fit $\left(R^{2}\right)$ is better.

Turning to another important statistical issue, we should consider the potential for an endogeneity problem. To deal with this, we reestimate (2a) and (2b), excluding the supply side and institutional variables of ABED and DCOVER. ${ }^{14}$ Column (3a) and (3b) in Table 4 correspond to the FE and RE estimations, respectively. By the specification test, the FE model of (3a) is selected as a suitable estimation. As for (3a), the results for the magnitude and significance of each coefficient are approximately the same as in (2a).

According to the estimations explained above, considering some statistical issues, the last model of (3a) can be interpreted as a robust result. To sum up, we can confirm the important point of this study: population ageing has an insignificant impact on health costs as found in many recent empirical studies, including Barros [5] and Zweifel et al. [13].

\subsection{A New Signal for the Determinants of Health Expenditures}

With the above analyses in mind, we next re-estimate the FE model under alternative sample periods to check robustness. The new sample periods are 1990-2006 and 1997-2006, while the explanatory variables and the sample countries are the same as in (3a). The results are shown in Table 5. Columns (4) and (5) present 1990-2006 and 1997-2006 estimations, respectively.

In (4), features of the income variable shown in this article are reproduced: $\partial \mathrm{HE} / \partial \mathrm{GDP}=\alpha<1$. We can therefore conclude that health care service is a necessary good. The estimate for POP65 is positive but insignifi-

Table 5. Estimation results (3).

\begin{tabular}{|c|c|c|}
\hline & (4) & (5) \\
\hline & 1990- & $1997-$ \\
\hline \multirow[t]{2}{*}{ GDP } & $0.955^{* * *}$ & $0.887^{* * *}$ \\
\hline & $(0.010)$ & $(0.021)$ \\
\hline \multirow[t]{2}{*}{ POP65 } & 0.024 & $0.192^{* *}$ \\
\hline & $(0.068)$ & $(0.085)$ \\
\hline \multirow[t]{2}{*}{ FLABOUR } & 0.046 & -0.042 \\
\hline & $(0.085)$ & $(0.135)$ \\
\hline \multirow[t]{2}{*}{ POPD } & 0.151 & $0.651^{* *}$ \\
\hline & (0.197) & $(0.242)$ \\
\hline \multirow[t]{2}{*}{ PUBE } & $0.330^{* * *}$ & 0.039 \\
\hline & $(0.070)$ & $(0.085)$ \\
\hline \multirow[t]{2}{*}{ UNEMPLOY } & $0.049^{* * *}$ & -0.005 \\
\hline & $(0.011)$ & $(0.016)$ \\
\hline \multirow[t]{2}{*}{ TIME } & $0.334^{* * *}$ & $0.515^{* * *}$ \\
\hline & $(0.041)$ & $(0.062)$ \\
\hline$R^{2}$ & 0.641 & 0.068 \\
\hline Observations & 393 & 221 \\
\hline
\end{tabular}

Note: See Table 3. ${ }^{14}$ The reason for excluding ABED and DCOVER is that these variables are likely to cause an endogeneity problem in the context of health
expenditures. 
cant, replicating previous findings in the literature. That is, the ageing rate and health expenditures are weakly related. Although the overall results of the estimation are close to those of (3a), the only distinct change is the estimate for FLABOUR. The coefficient has substantially smaller magnitude, and is insignificant at even the $10 \%$ level. In addition to the matter of ageing effects, this raises an interesting point in the present estimation.

Column (5) displays the results in a shorter sample period. Compared with the results already obtained in this study, these results are markedly different. The result for GDP accords with the previous estimates, but the result for POP65 is drastically altered. From this result, we can infer that the effects of ageing are strongly reflected in a sample constructed from more recent data. Taking account of the suggestion by Cutler [18], which was noted in the introduction, the positive and highly significant coefficient of POP65 likely indicates a signal of a critical transition in the health environment. Moreover, according to the insight by Dormont $e t$ al. [19] on the basis of Yang et al. [20], although death proximity supported by microeconometric studies is surely important as a determinant of health expenditures, the ageing effect still cannot be ignored. Our findings possibly relate to the insight gleaned from the regression analysis using cross-country panel data. However, some problems with the overall result of this estimation remain. We must bear in mind that the relatively short-run estimation of (5) has less credibility in comparison with our previous estimates. Specifically, the results of these estimates differ markedly, except for the two fundamental variables and the proxy variable for technological change (TIME). ${ }^{15}$ In addition, the substantial deterioration in $R^{2}$ exemplifies the problem. Therefore, the result for POP65 in the last estimation should be treated provisional, but might be a new signal for ageing effects on health costs.

\section{Conclusions}

Using a panel of 25 OECD countries over the periods 1985-2006, 1990-2006, and 1997-2006, this study comprehensively examined the determinants of health expenditures. We focused in particular on the estimated coefficient for the ratio of the population aged 65 and over (POP65) as a proxy for population ageing under various model specifications with many control variables. There were three main results obtained from this study. First, the benchmark estimation of (1b) through a set of standard tests in a panel study found insignificant ageing effects. Second, this result was clearly confirmed in the estimations dealing with possible econometric problems. Our result is therefore robust and consistent with recent empirical evidence in the literature. Third, which is foremost achievement of this paper, in the 1997-2006 estimation conducted to check robustness, we found significant ageing effects contrary to our previous regressions. This unique result calls for reconsidering the stylized relationships between population ageing and health care expenditures, and represents a possible new signal. ${ }^{16}$ It also indicated the essential need to continue observing the impacts of a country's age structure on health costs.

Other important findings are that 1 ) the estimated income elasticities obtained in this study are smaller than unity, implying that health care service is a necessary not luxury good; 2) along with GDP, FLABOUR, POPE, UNEMPLOY, and TIME also appeared to affect health expenditures in the robust long-term sample of 19852006; and 3) among these variables in particular, TIME exhibited high significance in all estimations as a proxy for technological change in the health sector; this has been frequently mentioned, including by Newhouse [24], because taking account of technological change is crucial for investigating the key factors related to rising health costs.

The subject of this paper warrants further study in greater detail. Under a similar framework, an additional investigation with a longer sample period is needed to determine whether the stylized facts advocated in the microeconometric literature (i.e., insignificant ageing effects) and the new signal captured by the present analysis (i.e., significant ageing effects) is probable. Such investigation is needed in order to formulate better health care policies. In addition, to resolve the potential endogeneity problem, we should employ instrumental variables estimation. Such an approach will make it possible to conduct an analysis with greater credibility.

\section{Acknowledgements}

The author would like to thank an anonymous referee for valuable comments and helpful suggestions. This work

\footnotetext{
${ }^{15}$ The coefficient for TIME exhibits a high significance with the expected sign. This likely indicates rapid year-to-year progress in medical technologies, and deserves careful attention.

${ }^{16}$ However, as indicated in the last part of the previous section, some problems with the overall result of this estimation remain.
} 
was financially supported by Grant-in-Aid for Young Scientists (B) 20730163 and 24730251 from JSPS KAKENHI. Any remaining errors are my own responsibility.

\section{References}

[1] Getzen, T.E. (1992) Population Aging and the Growth of Health Expenditure. Journal of Gerontology, 47, S98-S104. http://dx.doi.org/10.1093/geronj/47.3.S98

[2] Norton, E.C. (2000) Long-Term Care. In: Culyer, A.J. and Newhouse, J.P., Eds., Handbook of Health Economics, Vol. 1B, Elsevier, Amsterdam, 956-994. http://dx.doi.org/10.1016/S1574-0064(00)80030-X

[3] OECD (1996) Health Care Reform: The Will to Change. OECD, Paris.

[4] Hitiris, T. and Posnett, J. (1992) The Determinants and Effects of Health Expenditure in Developed Countries. Journal of Health Economics, 11, 173-181. http://dx.doi.org/10.1016/0167-6296(92)90033-W

[5] Barros, P.P. (1998) The Black-Box of Health Care Expenditure Growth Determinants. Health Economics, 7, 533-544. http://dx.doi.org/10.1002/(SICI)1099-1050(199809)7:6<533::AID-HEC374>3.0.CO;2-B

[6] Gerdtham, U.-G., Jönsson, B., MacFarlan, M. and Oxley, H. (1998) The Determinants of Health Expenditure in the OECD Countries: A Pooled Data Analysis. In: Zweifel, P., Ed., Health, the Medical Profession, and Regulation, Kluwer, Academic Publishers, Dordrecht, 287-310.

[7] Herwartz, H. and Theilen, B. (2003) The Determinants of Health Care Expenditure: Testing Pooling Restrictions in Small Samples. Health Economics, 12, 113-124. http://dx.doi.org/10.1002/hec.700

[8] Gerdtham, U.-G. and Jönsson, B. (2000) International Comparisons of Health Expenditure: Theory, Data and Econometric Analysis. In: Culyer, A.J. and Newhouse, J.P., Eds., Handbook of Health Economics, Vol. 1A, Elsevier, Amsterdam, 11-53.

[9] Di Matteo, L. and Di Matteo, R. (1998) Evidence on the Determinants of Canadian Provincial Government Health Expenditures: 1965-1991. Journal of Health Economics, 17, 211-228. http://dx.doi.org/10.1016/S0167-6296(97)00020-9

[10] Wang, Z. (2009) The Determinants of Health Expenditures: Evidence from US State-Level Data. Applied Economics, 41, 429-435. http://dx.doi.org/10.1080/00036840701704527

[11] Felder, S., Werblow, A. and Zweifel, P. (2010) Do Red Herrings Swim in Circles? Controlling for the Endogeneity of Time to Death. Journal of Health Economics, 29, 205-212. http://dx.doi.org/10.1016/j.jhealeco.2009.11.014

[12] Werblow, A., Felder, S. and Zweifel, P. (2007) Population Ageing and Health Care Expenditure: A School of "Red Herrings"? Health Economics, 16, 1109-1126. http://dx.doi.org/10.1002/hec.1213

[13] Zweifel, P., Felder, S. and Meier, M. (1999) Ageing of Population and Health Care Expenditure: A Red Herring? Health Economics, 8, 485-496. http://dx.doi.org/10.1002/(SICI)1099-1050(199909)8:6<485::AID-HEC461>3.0.CO;2-4

[14] Dow, W.H. and Norton, E.C. (2002) The Red Herring That Eats Cake: Heckit versus Two-Part Model Redux. Triangle Health Economics Working Paper No. 1, University of North Carolina at Chapel Hill, Chapel Hill.

[15] Getzen, T.E. (2001) Aging and Health Care Expenditures: A Comment on Zweifel, Felder and Meiers. Health Economics, 10, 175-177. http://dx.doi.org/10.1002/hec.593

[16] Salas, C. and Raftery, J.P. (2001) Econometric Issues in Testing the Age Neutrality of Health Care Expenditure. Health Economics, 10, 669-671. http://dx.doi.org/10.1002/hec.638

[17] Seshamani, M. and Gray, A. (2004) Ageing and Health-Care Expenditure: The Red Herring Argument Revisited. Health Economics, 13, 303-314. http://dx.doi.org/10.1002/hec.826

[18] Cutler, D.M. (2003) Disability and the Future of Medicare. New England Journal of Medicine, 349, 1084-1085. http://dx.doi.org/10.1056/NEJMe038129

[19] Dormont, B., Martins, J.O., Pelgrin, F. and Suhrcke, M. (2010) The Growth of Health Expenditures: Ageing vs. Technological Progress. In: Garibaldi, P., Martins, J.O. and van Ours, J., Eds., Ageing, Health, and Productivity, Oxford University Press, Oxford, 16-38. http://dx.doi.org/10.1093/acprof:oso/9780199587131.003.0004

[20] Yang, Z., Norton, E.C. and Stearns, S.C. (2003) Longevity and Health Care Expenditures: The Real Reasons Older People Spend More. Journal of Gerontology B: Social Sciences, 58, S2-S10.

[21] Baltagi, B.H. and Moscone, F. (2010) Health Care Expenditure and Income in the OECD Reconsidered: Evidence from Panel Data. Economic Modelling, 27, 804-811. http://dx.doi.org/10.1016/j.econmod.2009.12.001

[22] Mosca, I. (2007) Decentralization as a Determinant of Health Care Expenditure: Empirical Analysis for OECD Countries. Applied Economics Letters, 14, 511-515. http://dx.doi.org/10.1080/13504850500438736

[23] Crivelli, L., Filippini, M. and Mosca, I. (2006) Federalism and Regional Health Care Expenditures: An Empirical Ana- 
lysis for the Swiss Cantons. Health Economics, 15, 535-541. http://dx.doi.org/10.1002/hec.1072

[24] Newhouse, J.P. (1992) Medical Care Costs: How Much Welfare Loss? Journal of Economic Perspectives, 6, 3-21. http://dx.doi.org/10.1257/jep.6.3.3

[25] Wooldridge, J.M. (2002) Econometric Analysis of Cross Section and Panel Data. The MIT Press, Cambridge. 
Scientific Research Publishing (SCIRP) is one of the largest Open Access journal publishers. It is currently publishing more than 200 open access, online, peer-reviewed journals covering a wide range of academic disciplines. SCIRP serves the worldwide academic communities and contributes to the progress and application of science with its publication.

Other selected journals from SCIRP are listed as below. Submit your manuscript to us via either submit@scirp.org or Online Submission Portal.
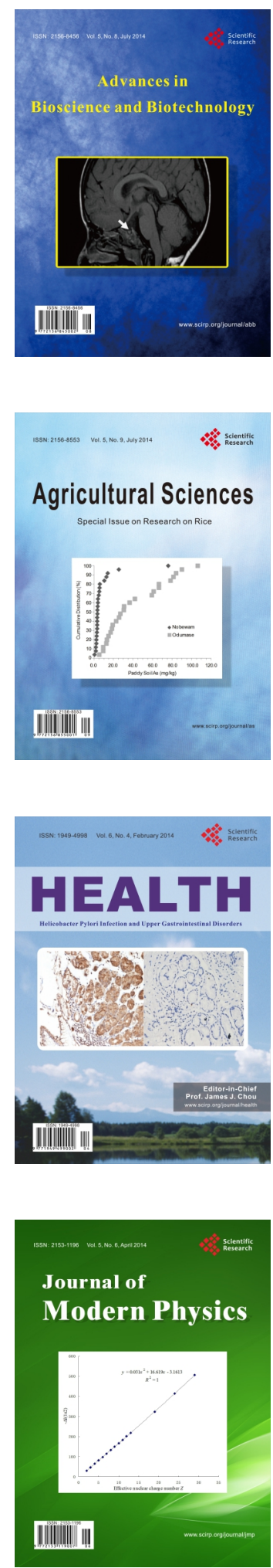
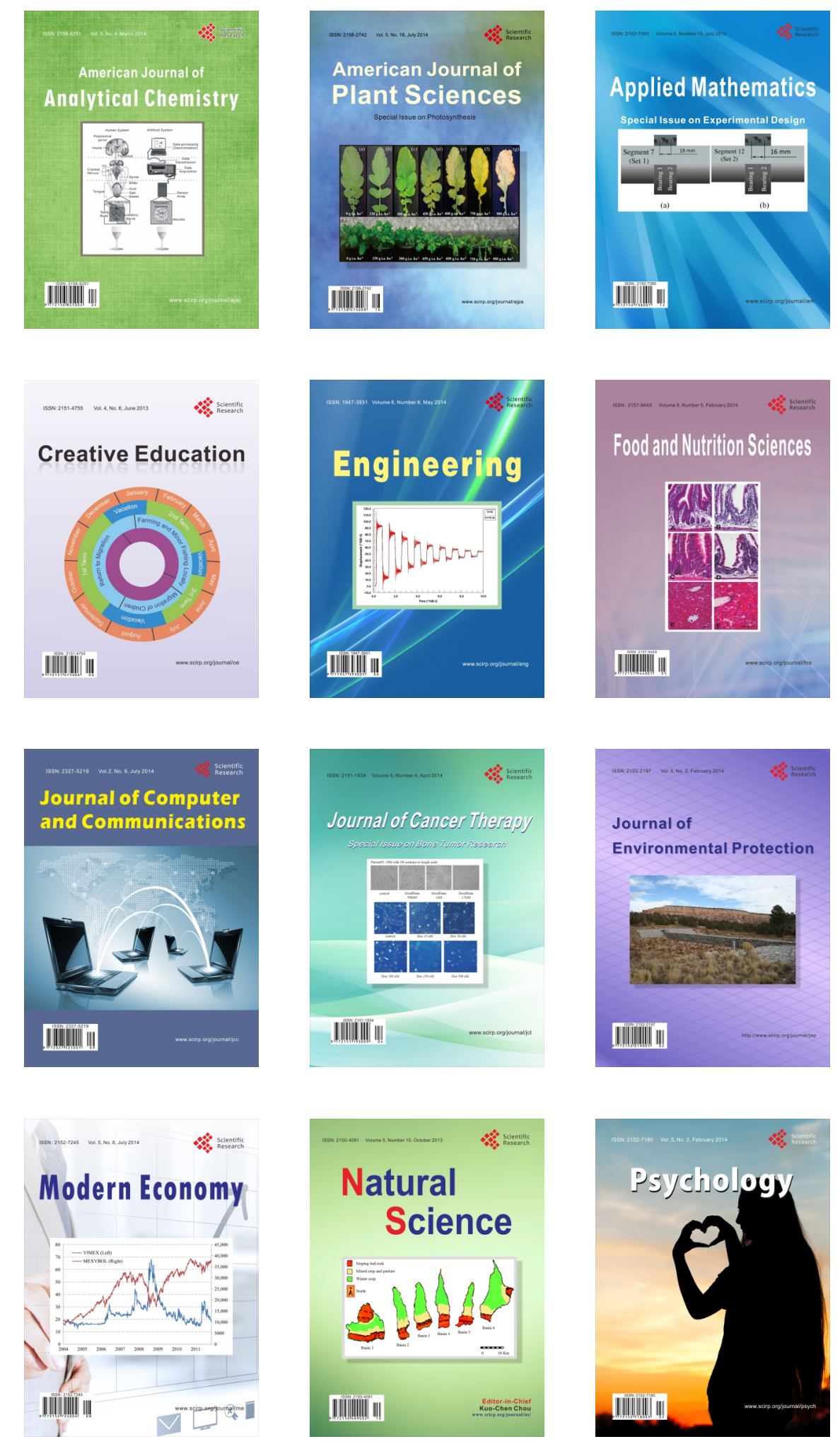